\title{
EL IMPACTO DE LAS COLADAS DE 1706 EN LA CIUDAD DE GARACHICO. (TENERIFE, ISLAS CANARIAS, ESPAÑA)
}

\author{
Carmen Romero Ruiz y Esther Beltrán Yanes \\ Área de Conocimiento de Geografía Física \\ Universidad de La Laguna
}

\section{RESUMEN}

Uno de los escenarios eruptivos de mayor importancia en Canarias es el asociado al desarrollo de erupciones basálticas fisurales, de comportamiento efusivo y localizadas en sectores de rifts volcánicos de bajas tasas eruptivas. El 80\% del volcanismo histórico producido en Canarias se ha localizado en estas estructuras y en el $60 \%$ de los casos las coladas se emplazan en ambientes litorales, densamente poblados, lo que las convierte en el riesgo volcánico más importante de las islas.

La erupción de Garachico ha sido el fenómeno volcánico histórico de mayor impacto socioeconómico de Tenerife. Entre el 5 de mayo y el 13 de junio de 1706 se emitió $0,045 \mathrm{~km}^{3}$ de materiales volcánicos que cubrieron un área de $7,6 \mathrm{~km}^{2}$. Este trabajo se centra en los daños vinculados al emplazamiento de las coladas en el sector litoral, pues fueron las causantes de las mayores pérdidas provocadas por la erupción.

Este estudio evidencia, asimismo, que el desarrollo de erupciones efusivas en rifts de este tipo obliga a contemplar no sólo los escenarios eruptivos más probables sino también los escenarios geográficos de inserción de las erupciones, pues éstos condicionan las modalidades de emplazamiento de los flujos lávicos y los riesgos derivados de ellos.

Palabras clave volcanismo histórico, riesgos volcánicos, erupción de Garachico, geografía del paisaje, Tenerife, Islas Canarias.

\section{ABSTRACT}

\section{The impact of lava flows of 1706 in the city of Garachico. (Tenerife, Canary Islands, Spain)}

One of the most significant eruption scenarios in the Canary Islands is that concerning the occurrence of effusive basaltic fissure eruptions in areas of volcanic rifts where there are low eruption rates. Eighty percent of historic volcanic activity produced in the Canary Islands has been located in these structures; and in $60 \%$ of the cases, the overspills occur in densely populated coastal areas, making them the most significant risk posed by volcanoes on the islands.

The eruption of Garachico had the greatest socioeconomic impact of any historical phenomenon that ever occurred on Tenerife. Between 5 May and 13 June 1706 , some $0.045 \mathrm{~km}^{3}$ of volcanic materials were emitted, covering an area of $7.6 \mathrm{~km}^{2}$. This paper focuses on the damage linked to the site of the overspills in the coastal area, as they were the cause of the greatest losses resulting from the eruption.

This study also shows that the occurrence of effusive eruptions on rifts of this type not only requires us to look at the most likely eruption scenarios but also the geographic scenarios involved in the eruptions, as these determine the location patterns of the lava flows and the risks arising from them.

Keywords: volcanic history, volcanic risks, Garachico eruption, landscape geography, Tenerife, Canary Islands.

\section{INTRODUCCIÓN}

Desde la época de la conquista de Tenerife llevada a cabo en 1496 se han producido en la isla cuatro episodios eruptivos, uno de ellos triple. Salvo la erupción de 1798 de Las Narices del Teide, ubicada en el flanco del estratovolcán de Pico Viejo, todos estos episodios se han emplazado en rifts volcánicos, derra- 
mando sus coladas hacia los sectores bajos de sus laderas. A comienzos del s XVIII se originó en Tenerife una etapa de inusual actividad eruptiva, ya que en menos de año y medio se produjeron las erupciones de Sietefuentes (1704), Fasnia (1705), Arafo (1705) y Garachico (1706), ocasionando los impactos más importantes vinculados a la actividad volcánica en tiempos históricos. A pesar de las diferentes historias de cada uno de estos episodios volcánicos, todos ellos parecen seguir un patrón común. Se trata de erupciones basálticas de carácter fisural acusado, con bajos índices de explosividad y abundante emisión de lavas (Romero, 1991).

Los daños generados por este tipo de erupciones están estrechamente vinculados a la población y características del poblamiento de las islas, tradicionalmente concentrados en los sectores altitudinales medios y de costa. En la actualidad, viven en Canarias más de 2.100.000 habitantes (ISTAC, 2013), correspondiéndole a Tenerife una población de 897.582 habitantes. La mayor concentración de la población de la isla en los sectores medios y costeros transforma las laderas bajas de los rifts volcánicos en las áreas de mayor riesgo por coladas de lava.

La realización de este trabajo se ha basado en la recopilación y análisis de la información histórica escrita y gráfica referida a la erupción de 1706, relacionándola con datos de carácter volcanológico, geológico y morfológico, lo que ha permitido establecer la historia eruptiva detallada de la erupción. La cartografía de los edificios volcánicos y de las distintas unidades lávicas de 1706 ha ayudado a realizar conexiones entre la zona de cumbres y de costa y ha posibilitado el conocimiento de las distintas secuencias eruptivas.

Asimismo, para establecer el impacto de este proceso eruptivo, se ha llevado a cabo un análisis conjunto de los datos referentes al paisaje previo y posterior a la erupción, siguiendo una valiosa metodología en la que se integran estos datos junto a los mencionados anteriormente. El establecimiento de los efectos que las coladas tuvieron sobre el territorio, la población y la ciudad de Garachico se fundamenta en la identificación y caracterización de la geografía que sustentaba la original fisonomía de este territorio. Para determinar este escenario general en el que se insertaba la antigua ciudad de Garachico, se han definido las relaciones espaciales establecidas entre sus componentes: vegetación, suelo, formas de relieves y modos de ocupación y uso por parte de sus habitantes, y valorado además el predominio relativo de éstos en su configuración fisonómica. La reconstrucción geográfica del paisaje y de la erupción se ha realizado también a partir de trabajo de campo, para la búsqueda de retazos de antiguas fisonomías del paisaje y de sus transformaciones a lo largo del tiempo.

Es llamativo que la erupción que mayor impacto ha causado en la población y en la historia de la isla cuente con el menor número de referencias escritas de todos los volcanes históricos de la isla de Tenerife. Cinco son los documentos básicos que se conservan de la erupción. Sólo tres de las descripciones parecen estar escritas por autores contemporáneos a los hechos, realizadas entre 1 y 6 años después de 1706. El texto de F. Juan García, Comisario del Santo Oficio de la Inquisición y Vicario Provincial de la Orden de San Francisco (1707), se conserva en el Biblioteca Nacional y fue publicado por primera vez en la prensa local tinerfeña hacia el año 1909. La descripción de Fray Domingo José Cassares (1706), Colegial del Convento de Sto. Domingo de La Laguna, se conserva en la Biblioteca de la Universidad de La Laguna y permanece aún inédito. La última crónica, de la cual se desconoce tanto el autor como el archivo de procedencia y la fecha de elaboración, fue recogida por Dacio Darías Padrón y publicada en la Revista de Historia de la Universidad de La Laguna el año 1931. Todos los textos son descripciones sucintas en las que apenas se alude a las características de la erupción y que se centran de modo exclusivo en los efectos y los daños provocados por las coladas en el puerto y la ciudad de Garachico. Junto a estos textos, la mayor parte de los autores del s XVIII, como Viera y Clavijo y Francisco Martínez de Fuentes que realizan descripciones de la isla de Tenerife, incorporan en sus trabajos alusiones a la erupción que ayudan a precisar los daños generados en el puerto y en las infraestructuras religiosas o civiles de carácter noble.

En contraposición a este reducido número de documentos en los que se describe la erupción, existe un excelente corpus gráfico, esencialmente cartográfico, previo y posterior al evento volcánico. Los mapas y planos permiten seguir la evolución planimétrica de la ciudad de Garachico desde el año de 1588, en que el ingeniero Leonardo Torriani levanta el primer plano detallado de la ciudad anterior a la erupción, hasta fines del s XIX, en que autores como Nuñez de La Peña (sin fecha precisa, s XVIII), Riviere (1741), Ingenieros Militares (1741), Francisco Coello (1849) y José Agustín Álvarez Rixo (1883), recogen diversos momentos de su evolución. Imágenes como las de Romain de Hooge, inserta en el mapa del Mar Mediterráneo publicado en Amsterdam (1693), el Diseño de la bahía y del Puerto de Garachico 
(Anónimo, 1702) ${ }^{1}$ y el grabado de Feuillée (1724), aportan también una visión de la ciudad previa y del trazado de las coladas en el entorno urbano. Toda esta información gráfica sirve de apoyo a los textos escritos, dotándolos de un contenido espacial que ha sido esencial en el estudio de la distribución geográfica de los daños asociados a la erupción.

Figura 1. Visión idealizada de la erupción de Garachico

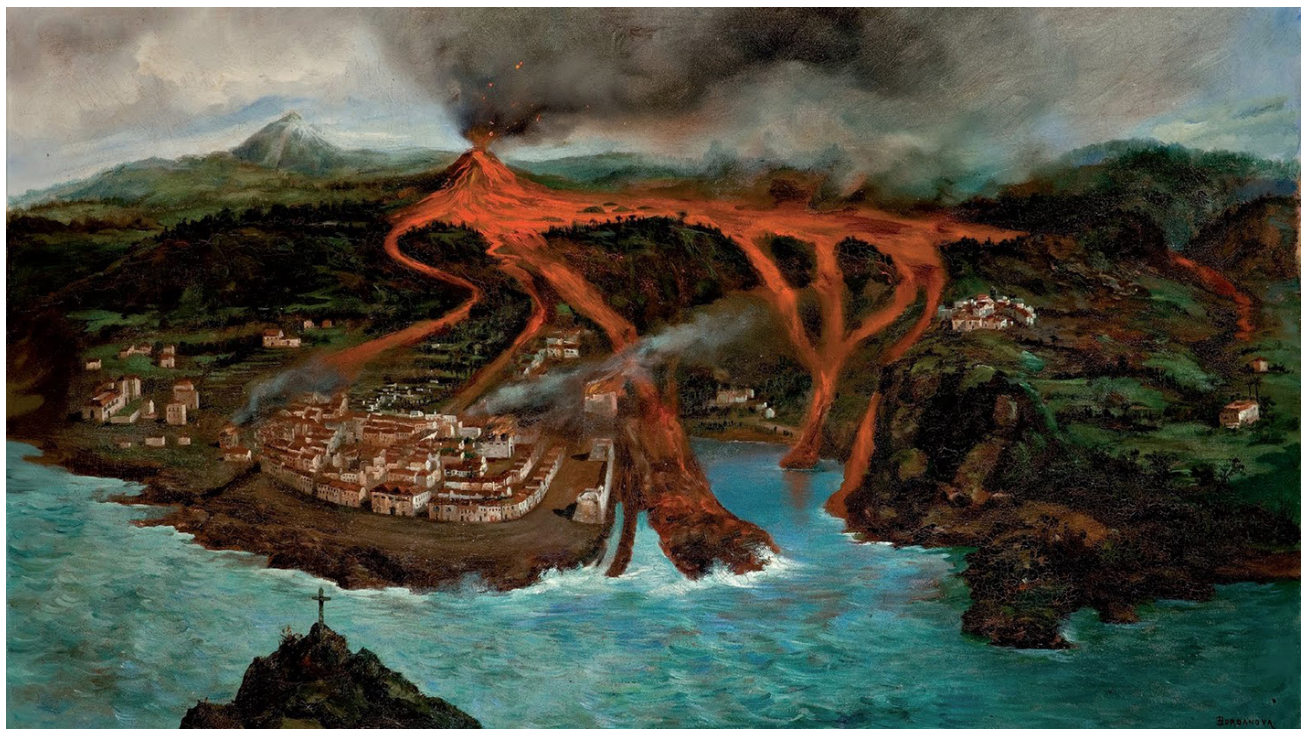

Fuente: Óleo de Ubaldo Bordanova. Colección particular. 1898

\section{CONTEXTO GEOLÓGICO Y GEOMORFOLÓGICO}

El volcanismo más antiguo de la isla de Tenerife se produjo entre 11,6 y 3.3 Ma y dio lugar a la construcción de los macizos antiguos de Teno, Anaga y Roque del Conde, localizados respectivamente al NW, NE y S de Tenerife. Tras el cese de la actividad volcánica que formó estos macizos antiguos, nuevas coladas de lavas basálticas se emitieron a través de centros de emisión concentrados preferentemente a lo largo de dos ejes volcanotectónicos, formando las dorsales NE-SW y NW-SE, dispuestas entre los antiguos macizos de Anaga y Teno y el edificio central Teide-Cañadas (Ancochea et al., 1990).

Los rifts o dorsales volcánicas como se les denomina en Canarias, constituyen las estructuras más relevantes y persistentes en el desarrollo de las islas volcánicas oceánicas (Carracedo et al., 2009). En Canarias, los rifts corresponden a edificios volcánicos que se han formado a partir de tasas eruptivas bajas, lo que determina una elevada relación de aspecto de las estructuras resultantes y una configuración del relieve muy sobresaliente. (Carracedo et al., 2009).

El rift NW de Tenerife, área de desarrollo de la erupción de 1706, se encuentra prácticamente recubierto por lavas generadas en los últimos 20.000 años; la mayoría de las erupciones de este período han generado frecuentes y extensas coladas máficas, muchas de las cuales han alcanzado la costa (Carracedo et al., 2003) y han dado lugar a la formación de deltas y plataformas lávicas costeras. Este sector de la isla corresponde a una zona que presenta una alta probabilidad de verse afectada por coladas de lava en el futuro (Araña et al., 2000).

Las dorsales constituyen estructuras en tejado a dos aguas de gran desarrollo longitudinal, caracterizadas por la concentración de conos en el área de cumbres y por tener laderas esencialmente lávicas. Geomorfológicamente, en los rifts volcánicos de tasas eruptivas bajas, pueden establecerse varias unidades espaciales (cumbres, laderas y costas) en función del grado de combinación de las formas volcánicas con las erosivas (Romero, 1991). Evidentemente, el sector litoral se inserta en el sistema morfogenético más activo de las dorsales (Yanes y Beltrán, 2009). Se trata, por tanto, de un área donde el grado de interferencia entre procesos volcánicos y erosivos es máximo y donde la convivencia de formas de erosión y

1 Toda la documentación gráfica citada hasta el momento puede consultarse en Tous Meliá, 1996 y 1997. 
sedimentación con las volcánicas es más acusado. Estos sectores que están más alejados de los centros de emisión, tienen menores probabilidades de verse afectados por coladas de lava y, al estar sometidos a la acción constante del oleaje, suelen caracterizarse por la presencia de importantes acantilados, cuya altura oscila entre los 100 y los $600 \mathrm{~m}$. La llegada de flujos lávicos a la costa determina que puntualmente estos cantiles queden retranqueados y se formen a su pie deltas y plataformas lávicas costeras de muy diferentes dimensiones y edades, tanto mono como policrónicas.

La fisonomía del sector costero septentrional del rift NW de Tenerife posee los rasgos descritos y está caracterizada por la presencia de un acantilado que se extiende por la costa NW de la isla con altitudes de entre 300 y $500 \mathrm{~m}$. A su pie, se desarrollan plataformas costeras de diferente amplitud superficial y que remiten a una historia geológica caracterizada por la intercalación de fases erosivas y fases de construcción volcánica (Fig. 2).

Figura 2. Mofoestructuras de Tenerife. Localización de la erupción de 1706 en el área de la dorsal de Abeque con gran desarrollo de coladas generadoras de plataformas lávicas costeras recientes

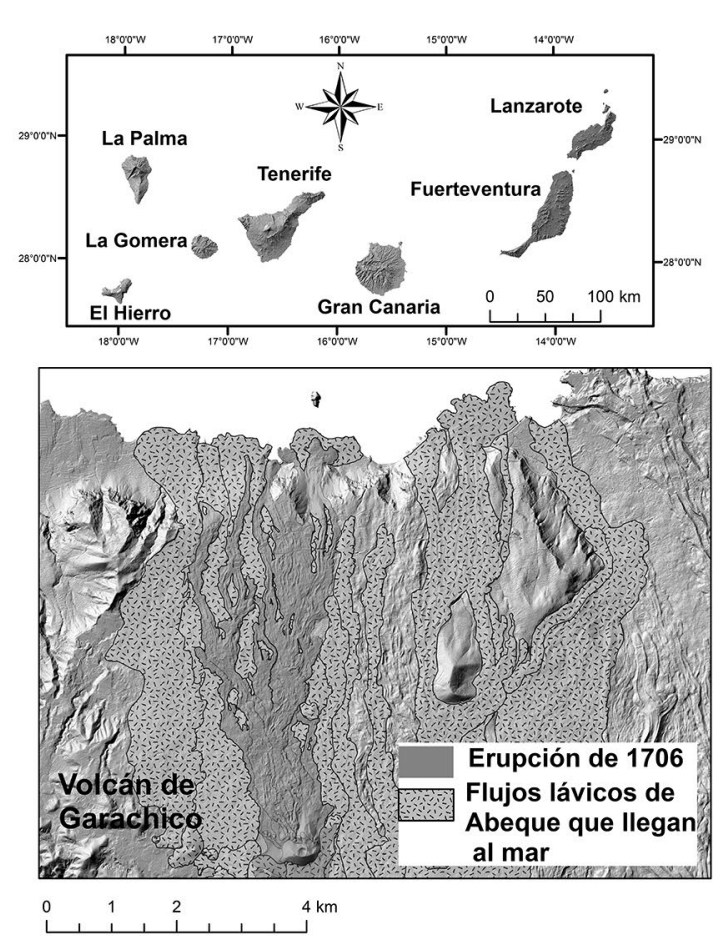

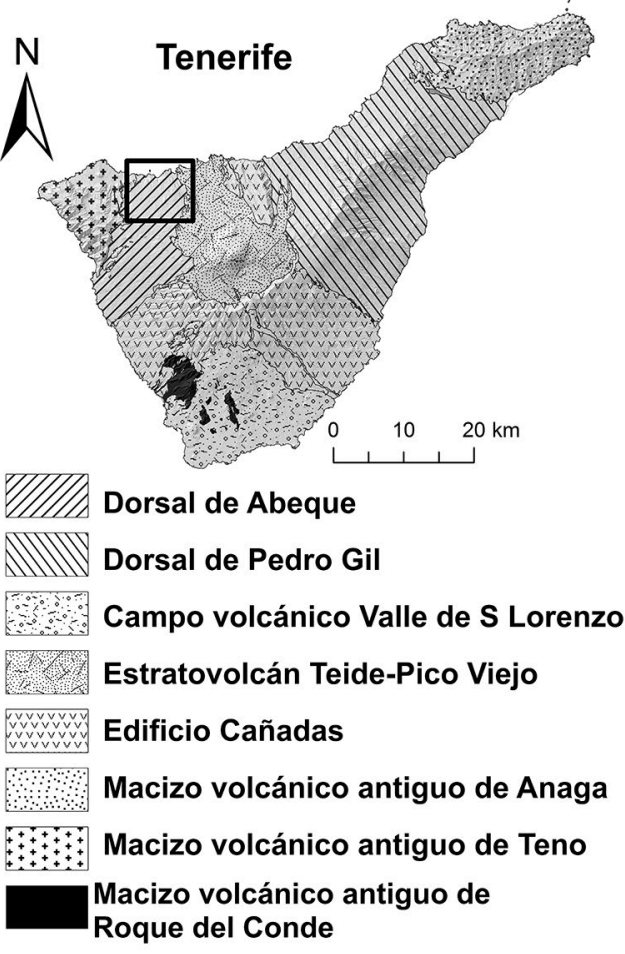

\section{EL PAISAJE ANTES DE LA ERUPCIÓN}

El paisaje general de la vertiente en la que se emplaza Garachico corresponde a un voluminoso relieve que surge del mar hasta casi alcanzar $2.000 \mathrm{~m}$ de altitud. Las laderas de este impresionante relieve montañoso se quiebran en la costa debido a la presencia de un acantilado de aproximadamente $500 \mathrm{~m}$ de altura que imprime una gran originalidad a su paisaje (Beltrán, 2000). Rompiendo el carácter abrupto del relieve, al pie del escarpe, destaca la topografía subhorizontal de una plataforma lávica policrónica de $0,49 \mathrm{~km}^{2}$ y de 3,3 km de perímetro costero (Yanes et al., 1988). Durante los s XVI y XVII, asociado a estas formas del relieve y bajo el efecto regular de los vientos húmedos del alisio, característicos de estas latitudes del Atlántico oriental, las cumbres y laderas aparecían cubiertas por amplios bosques de laurisilva y pinar, dejando entrever entre ellos las "cicatrices volcánicas" recientes de este sector de la isla. El agua, procedente de la condensación de la niebla y de las lluvias en las laderas cubiertas de bosques situadas a mayor altitud se filtraba por suelos volcánicos porosos, muy abundantes en la mayor parte de la vertiente y afloraban predominantemente en el sector de los acantilados como fuentes o manantiales. Sólo en las tierras bajas, más cercanas al mar, la masa forestal desaparecía y era sustituida por un matorral de adaptaciones xerófilas, indicando el dominio local de un ambiente semiárido. 
En el litoral, los rasgos climáticos, la topografía y las características del volcanismo determinaron la existencia de dos unidades espaciales, con posibilidades de usos muy diferenciados de cara a su ocupación humana. De un lado, el escarpe y los taludes inferiores localizados a su pie; de otro, la plataforma lávica inferior.

\subsection{El acantilado con bosques termófilos, matorrales xerófilos y parcelas de cultivos}

La primera unidad de paisaje aparecía suspendida en la vertical, coincidiendo con el imponente escarpe costero que tanta identidad paisajística ha proporcionado a la ciudad de Garachico. El apilamiento de antiguos materiales lávicos se presentaba limpiamente cortado por el intenso y prolongado efecto de zapa del mar en su base y fosilizado por los aportes de lava recientes que llegaron al litoral, o por los materiales detríticos procedentes de la erosión del acantilado. Por aquellos siglos, en estas paredes rocosas se identificaban expresiones de bosques de laurisilva pertenecientes a la comunidad Lauro novocanariensis-Perseetum indicae (del Arco et al., 2006), favorecidas por la presencia de nacientes de agua, y otras de bosques esclerófilas, de gran afinidad con el mundo mediterráneo, correspondientes al sabinar-acebuchal (Junipero canariensis-Oleetum cerasiformis) en los sustratos más secos y rocosos, alternándose con palmerales canarios (Periploco laevigatae-Phoenicetum canriensis). Parte de estas manifestaciones arbóreas persisten de forma muy discontinua en el paisaje actual colindante al sector afectado por la erupción. Todos estos componentes del paisaje se combinaban en el espacio configurando un especial mosaico de variadas unidades de paisaje internas, a las que también se adaptaba el uso y aprovechamiento humano. Autores de la época destacaron la belleza natural y la riqueza agrícola que tenía este sector de Garachico: “...servianle de penachos à estos riscos/laureles, sauces, pinos y obeliscos, /y en varias partes servia á su hermosura/de hiedras una hermosura colgadura,/teniendo para ser cabal y entera,/senefas de enlazada gilbaluera./ Poblavanle unas vides escuadronas, /y haciendo de sus pampanos pendones/ formavan en los riscos sus carreras, / sin reparar de hallarse en las laderas, tan llenas de placer y alegrías/ que bien mostraban ser de malvasías" (Cassares, 1709, fol2v).

Por tanto, en el acantilado se reconocían espacios cultivados por medio de bancales en los retrocesos por erosión remontante de los sectores más altos y en los taludes de derrubios, cuyas laderas de menor pendiente permitían el aprovechamiento agrícola. En estos lugares se plantó primero caña de azúcar y luego vid. Los sectores cultivados se alternaban espacialmente con los bosques citados y matorrales xerófilos y termófilos de las paredes más verticales (Romero y Beltrán, 2007) (Fig. 3).

Figura 3. Aproximación a la organización espacial de los usos y ocupación del suelo en la costa de Garachico antes de la erupción de 1706

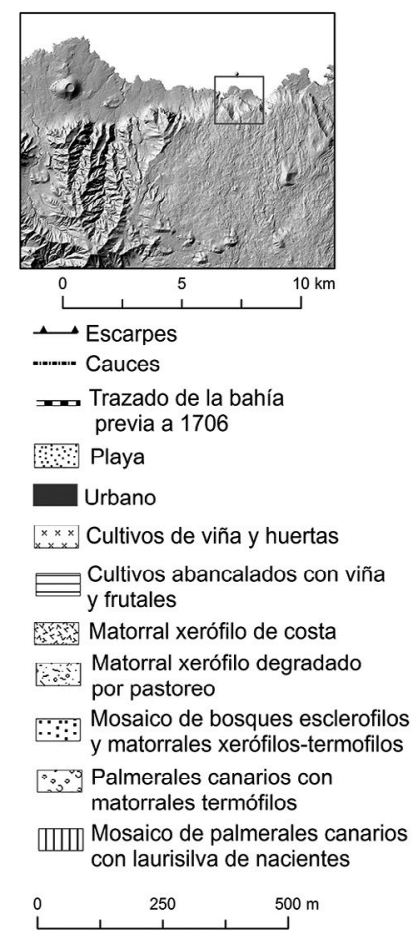

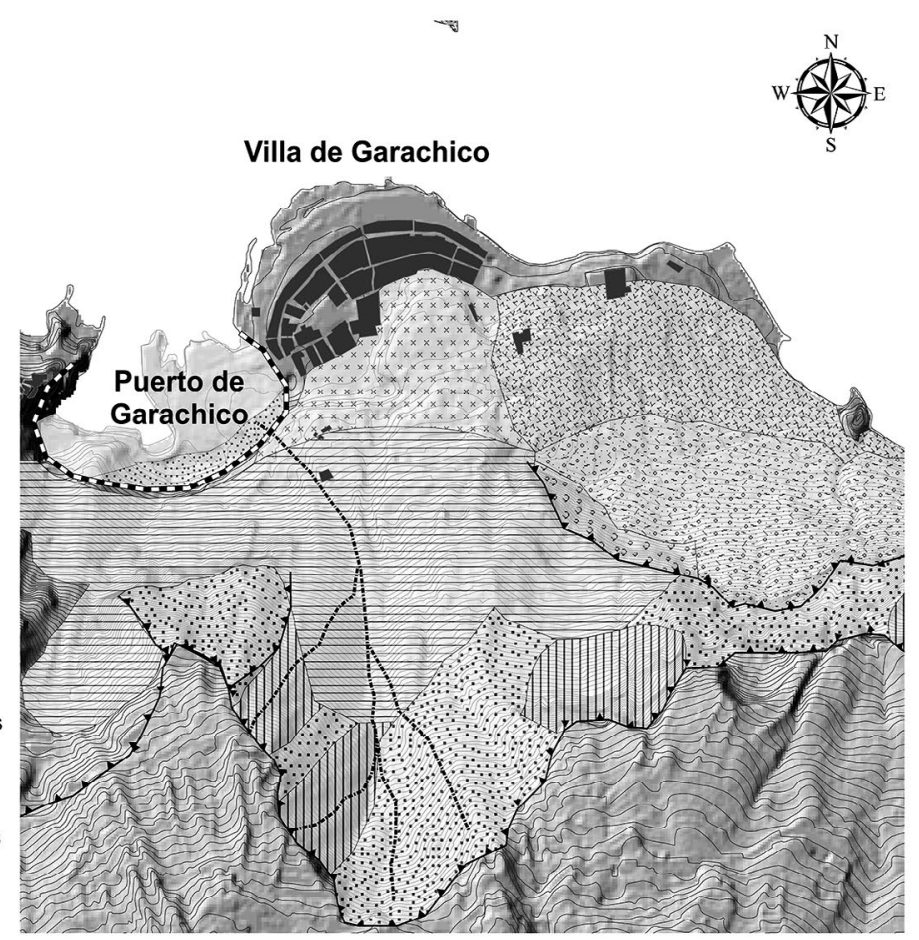




\subsection{La costa volcánica con fincas de hacendados y la antigua Villa de Garachico}

El espacio estrictamente costero de Garachico antes de la erupción de 1706 era, y sigue siendo en la actualidad, no muy amplio y se reducía a una estrecha franja espacial situada al pie del acantilado. El trazado en planta de esta unidad tenía un dibujo festoneado creado por la llegada al mar de las coladas lávicas del pleistoceno y holoceno que se descolgaron por un antiguo acantilado plio-pleistoceno (Bellido et al., 1989). Fruto de su constitución por materiales lávicos de naturaleza básica es el carácter pedregoso, caótico y de difícil tránsito que distingue a las lavas de formas aa y en bloques, predominantes en el delta lávico. Otro de los rasgos paisajísticos que identificarían la geografía de este sector era la presencia en el delta lávico de un matorral de adaptaciones xerófilas, denominado cardonal (Periploco laevigatae- Euphorbietum canariensis (del Arco et al., 2006), en las que la suculencia de los tejidos es frecuente, de ahí su afinidad con la vegetación de ambientes desérticos de la costa africana. Este matorral, reconocible en la actualidad en algunos sectores próximos, se organizaba en un paisaje vegetal controlado fundamentalmente por la influencia de la maresía y las características del sustrato (Romero y Beltrán, 2007). Hacia el área de contacto con el escarpe, las superficies lávicas estaban parcialmente recubiertas por los taludes de derrubios y recortadas por el Barrano de Los Reyes, formado durante el aluvión de 1645 (Darías Padrón, 1931), que terminaba en una playa del interior de la bahía.

No obstante, no todo el delta lávico de Garachico poseía las mismas condiciones para el aprovechamiento agrícola e instalación de la población. En el corto espacio de la plataforma lávica, que apenas alcanzaba unos 700 metros de longitud máxima, existían al menos tres franjas claramente definidas, con rasgos particulares de cara a su ocupación por el hombre.

En primer lugar, un sector litoral muy irregular, correspondiente a frentes de derrames de lava erosionados, batido frecuentemente por un mar bravo. Las olas de los temporales eran capaces de penetrar tierra adentro hasta casi un centenar de metros. Así, junto a su condición de terreno volcánico áspero propio de los malpaíses, había que unir la fragilidad derivada de su emplazamiento costero. De hecho, con anterioridad a la erupción de 1706, se tiene constancia documental del desarrollo de al menos dos temporales marinos importantes en los años 1559 (Frutuoso, 1522-1591) y 1591 (Rodríguez Yanes, 1988). Sin embargo, en contrapartida, esta zona poseía algunas ventajas, pues constituía una costa que: "está bien defendida, porque está rodeada de un malpaís (que así le dicen alli), que son piedras quemadas por los volcanes antiguos, que impiden el desembarco (Torriani, 1592-1599). Un litoral, en definitiva, que protegería de los ataques e incursiones de los enemigos y piratas a la ciudad.

Tras la línea costera estricta, existía una franja constituida por tierras igualmente difíciles, caóticas y pedregosas, correspondientes también a coladas de lava, cuya pendiente aumentaba ligeramente hacia el sur, aunque configuraban los sectores de topografía más suave de la plataforma lávica. Este sector destinado inicialmente por el primer Adelantado, D. Alfonso Fernández de Lugo, para uso urbano, presentaba ciertos problemas para tal fin, pues requería de grandes gastos para su acondicionamiento por la irregularidad de las superficies lávicas. En un documento de 1541 se señalan ya las dificultades que supuso la ocupación humana en el entorno de Garachico: "se ha poblado y fundado muy junto al mar, sobre malpaíses y riscos y tierra inutil, y por ser de tal calidad, fue dado para población por el Adelantado, y las personas que han edificado sus casas, ha sido trayendo tierra de otra parte para entullarlo, quebrando grandes peñas y riscos..." (Cionarescu, 1977: 11).

A mayor altura, hacia la base del acantilado, los taludes, que ocupaban y aún ocupan en la actualidad un estrecho espacio de elevada pendiente, con mejores posibilidades para el cultivo. Por su situación casi al pie del escarpe, estas tierras tenían además la ventaja de su mayor cercanía a los puntos de abastecimiento de agua, tan necesaria para el cultivo inicial de la caña de azúcar.

Por encima de estas tres franjas, el propio risco, con fuertes pendientes y dispuesto como una auténtica muralla rocosa, que cerraba la ciudad por el sur y que albergaba las fuentes y manantiales que suministraba el agua para los cultivos, el consumo humano y el propio puerto.

\subsection{La ocupación y uso del suelo en la villa de Garachico antes de 1706}

Tras los repartimientos de tierra, cada zona fue utilizada para un uso diferente, cada franja fue ocupada por un grupo social distinto, de modo que el espacio se organizó jerárquicamente. En el sector central, cerca del área cultivada, con mejores condiciones para el abastecimiento de agua, y lejos de la zona afectada por los embates del mar, se instalaron los grandes propietarios. En este sector se construirían los edi- 
ficios más suntuosos y los edificios públicos, con abundante madera de tea². Tras ellos, hacía el risco, las tierras de labor y pastoreo del entorno de la ciudad. En la franja del malpaís costero, de condiciones más duras, se instalaron los vecinos, artesanos, mercaderes y marineros, en casas pobres (Cionarescu, 1977).

En 1510, Garachico contaba con sólo 10 casas; en 1549 la villa se articulaba en torno al puerto y poseía una única calle ya empedrada (Cionarescu, 1977). Sólo treinta y nueve años después, en 1588, Leonardo Torriani, un ingeniero del rey español Felipe II, levanta un plano de la ciudad en el que se observa ya una trama urbana plenamente desarrollada (Fig. 4). Esta imagen es el documento gráfico más antiguo de la ciudad completa de Garachico y en ella aparecen localizados los principales edificios civiles y religiosos. Constituye, por tanto, un documento de referencia de primer orden para valorar con precisión los efectos que las coladas tuvieron sobre la ciudad y el puerto.

Figura 4. Plano de la ciudad de Garachico levantado por Leonardo Torriani hacia 1588

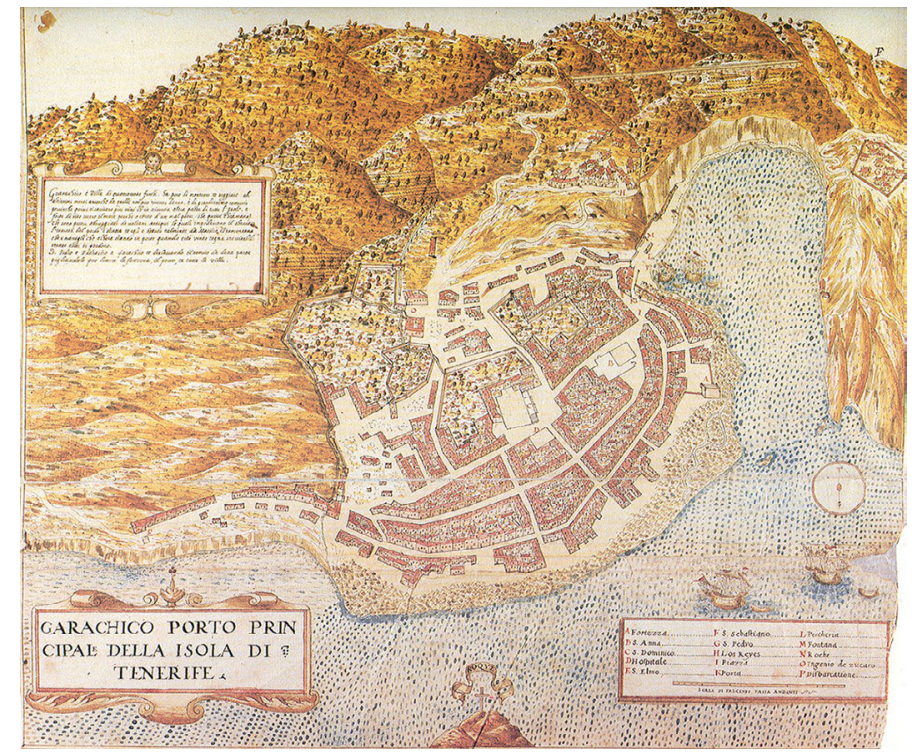

Fuente: (Martín Rodríguez, 1986:105).

La ciudad de esos momentos poseía una planta en abanico, totalmente adaptada a su construcción sobre un delta lávico reciente y articulada en torno a tres ejes principales de disposición arqueada: las calles de Arriba, de El Medio y de Abajo. En la calle de Arriba se localizaban los edificios más importantes y emblemáticos de la ciudad, protegidos de los embates del mar que esporádicamente afectaban a la villa.

La estructura urbana de Garachico desarrollada durante la etapa de apogeo económico de los s XVI y XVII, y ligada fundamentalmente a la explotación y al comercio del vino (Martínez Galindo, 1998), siguió manteniendo la articulación socialmente jerarquizada del espacio de sus inicios. No obstante, la ciudad afectada por la erupción de 1706 no es la misma que recoge Torriani en su magnífico plano. Durante los 60 años previos al fenómeno volcánico, Garachico se vio sometido a toda una serie de calamidades; en 1645, un aluvión provocó la muerte de 100 personas, la destrucción de 80 casas en el Barrio de Los Reyes y la colmatación parcial de la bahía, con la desaparición de 14 barcos (Darías Padrón, 1931; Cioranescu, 1977). En 1692 y 1696 dos incendios urbanos destruyeron más de 110 casas y el convento agustino (Darias Padrón, 1931; Cioranescu, 1977). Estos sucesos afectaron a las áreas más vulnerables de la población y desdibujaron parcialmente su estructura urbana en el área próxima al litoral y en el sector de los taludes interiores.

El acelerado desarrollo de la ciudad de Garachico estaba vinculado a la existencia de una pequeña bahía natural, antiguamente denominada Caleta del Genovés, situada en la vertiente septentrional de Tenerife. Esta bahía constituía una referencia geográfica de primer orden y una seña de identidad precisa de Tenerife, como se observa en las primeras imágenes que se poseen de la isla. El puerto era una pequeña

2 Madera resinosa, muy resistente, extraida de los pinos canarios añosos. Se empleaba principalmente en carpintería de obras de fábrica, como iglesias y casonas. http://www.academiacanarialengua.org/buscar/? q=tea\&search-button. $\mathrm{x}=0$ \&search-button. $\mathrm{y}=0$ 
ensenada en forma de herradura de 334,4 m de ancho y 300,98 m de longitud, con una boca de entrada de $547,2 \mathrm{~m}$ y unos $50 \mathrm{~m}$. de profundidad (Escribano, 2003).

Desde la época inmediatamente posterior a la conquista, prácticamente toda la actividad comercial ya fuera local, nacional o internacional estaba centrada en este pequeño puerto. Primero asociada a la existencia de ingenios azucareros y luego a la exportación de vinos de malvasía. Garachico constituyó durante el s XVI una de las principales poblaciones de la isla; el segundo núcleo poblacional después de la capital, establecida en esos momentos en la ciudad de San Cristóbal de La Laguna.

La prosperidad del puerto de Garachico se refleja no sólo en el aumento espectacular de la población, sino también en el ritmo con que se expandió la ciudad. El desarrollo económico y social del Garachico del s XVI es fruto de la conjunción de varios hechos. Por un lado, de una orografía insular tremendamente contrastada que dificultaba la existencia de buenas comunicaciones terrestres y que favoreció el tráfico marítimo frente al terrestre, incluso para el comercio local. Y por otro, de las excepcionales características de la Caleta del Genovés que hacían del puerto de Garachico el principal fondeadero para la comercialización de productos de exportación, principalmente azúcar y vino, de un amplio sector del norte de la isla. El puerto de Garachico formaba parte, por tanto, de un circuito económico y comercial internacional que vinculaba la isla con Europa, África y América.

No obstante, aunque el comercio del vino siguió jugando un papel importante como motor económico de la ciudad, no conservaría a lo largo del s XVII el empuje que había tenido en el s XVI. La competencia y rivalidad de otros puertos insulares, como el de Santa Cruz o el de La Orotava, y la sucesión de toda una serie de episodios catastróficos supusieron un freno al desarrollo y al mantenimiento del puerto y la villa de Garachico como núcleo comercial más importante de Tenerife. A partir de 1633 el puerto de Garachico pierde su primacía frente a los de La Orotava y Santa Cruz y la situación internacional ya no le era tan favorable. En 1704, Inglaterra firmó con Portugal el tratado de Methuen, que daba prioridad a los caldos de Madeira frente a los de Canarias. Paralelamente, la guerra de Sucesión Española produjo también un cambio sustancial en las relaciones comerciales de Canarias con Inglaterra que provocó la salida de la isla de una importante proporción de comerciantes europeos (Rodríguez Yanes, 1988). Se trata, por tanto, de un período de clara recesión económica que culminaría con el desastre volcánico de 1706.

En definitiva, la topografía y el carácter volcánico de este sector determinan la articulación territorial de su ocupación. El acantilado presentaba, como es lógico, una menor ocupación humana debido a su topografía adversa, aunque concentraba uno de sus principales recursos naturales a través de la presencia de fuentes y manantiales. En la costa, gracias a este recurso, el clima cálido de costa y los acondicionamientos del suelo volcánico, se encontraba el entorno agrícola de productos de exportación junto a la próspera ciudad y su puerto.

\section{LA ERUPCIÓN DE GARACHICO}

La descripción de la erupción de Arenas Negras o de Garachico se basa en la información obtenida en los documentos históricos contemporáneos a la erupción, de antiguos croquis, grabados y mapas, y de observaciones geomorfológicas y volcanológicas de campo.

Historiadores insulares del s XVIII describen que tras la erupción de Sietefuentes-Fasnia-Arafo, durante la segunda mitad del año 1705 y comienzos de 1706, se produjo en la isla de Tenerife una importante crisis sísmica: "Aunque se apagó al fin este volcán [se refiere al volcán de Arafo de 1705], los terremotos permanecieron más de un año; cuyas confusiones, extremecimiento de los edificios y haciendose sentir más fuertemente, acompañados de ruidos subterráneos, principalmente en el Valle de La Orotava...no permitiendo a los habitadores vivir en las casas sino en tiendas de campaña en los despoblados..." (Martínez Fuentes, s XVIII, en Romero, 1991: 505)

Tanto la frecuencia de los sismos como su intensidad aumentaron en los momentos previos al inicio de la erupción. Refiere Fray Domingo Josef Cassares que en la noche del 4 al 5 de mayo de 1706, hacia las 8 de la noche, comenzaron a sentirse terremotos tan fuertes que "veianse sepulcros con efectos de querer arrojar los cuerpos muertos y en las casas empezaban a sentirse los techos bulliciosos, hasta rendirse, oianse las campanas que con sentidos golpes parecía que tocaban a agonía..."(Cassares, 1709, fol. 9), llegando a alcanzar intensidades VII y VIII.

Esta situación se mantuvo durante toda la noche y una hora antes de amanecer (Fr. Juan Garcia, 1707), tras el cese momentáneo de los sismos, resonó bruscamente un estallido a lo lejos (Cassares, 1709). Coincidiendo con dicha explosión, en los sectores altos de Garachico a una altitud de 1300 m y a 
unos 6,5 km de la ciudad, se produjo la apertura de una fractura de unos $950 \mathrm{~m}$ de longitud, con más de 12 focos eruptivos y de dirección NW-SE que abarcaba una diferencia altitudinal de casi 100 metros entre sus extremos (Romero, 1991).

La erupción presentó desde su inicio un comportamiento típico de las erupciones basálticas subaéreas, muy similar al descrito en otras erupciones históricas de la isla, como ponen de manifiesto los depósitos de piroclastos asociados a los centros eruptivos y las formas que éstos presentan. Durante los momentos iniciales, a lo largo de la fractura se generaron fuentes de lava que edificaron pequeños coneletes de spatter desportillados hacia el norte (Fig. 5-B) por la salida de corrientes lávicas muy fluidas de tipo pahoehoe (Fig. 5 A y B, $\mathrm{n}^{\circ} 1$ ). Estas coladas llegaron a alcanzar recorridos superiores a los 2,5 km de longitud. En la actualidad, estos edificios quedan cubiertos por los piroclastos emitidos posteriormente por los cráteres principales surorientales.

El mismo día 5 de mayo se produjo la concentración de la actividad en el tramo suroriental, pues los flujos lávicos principales tienen siempre su punto de origen en los dos cráteres situados en este tramo de la fractura. Estas coladas ponen de manifiesto no sólo una emigración de la actividad eruptiva desde el NW hacia el SE de la fractura inicial, sino también la concentración de la misma en su tramo suroriental. A lo largo de del día 5 de mayo la erupción fue evolucionando progresivamente hacia mecanismos de carácter estromboliano, con explosiones discretas a intervalos de varias por minuto. Los productos emitidos en este sector de la fractura (lapillis, escorias y bombas de tipo fusiforme), comenzaron a formar un cono de mayor desarrollo en altura y un campo de lapilli, orientado por el viento hacia el sur y suroeste de la fractura (Fig. 5).

Figura 5. La erupción de Garachico

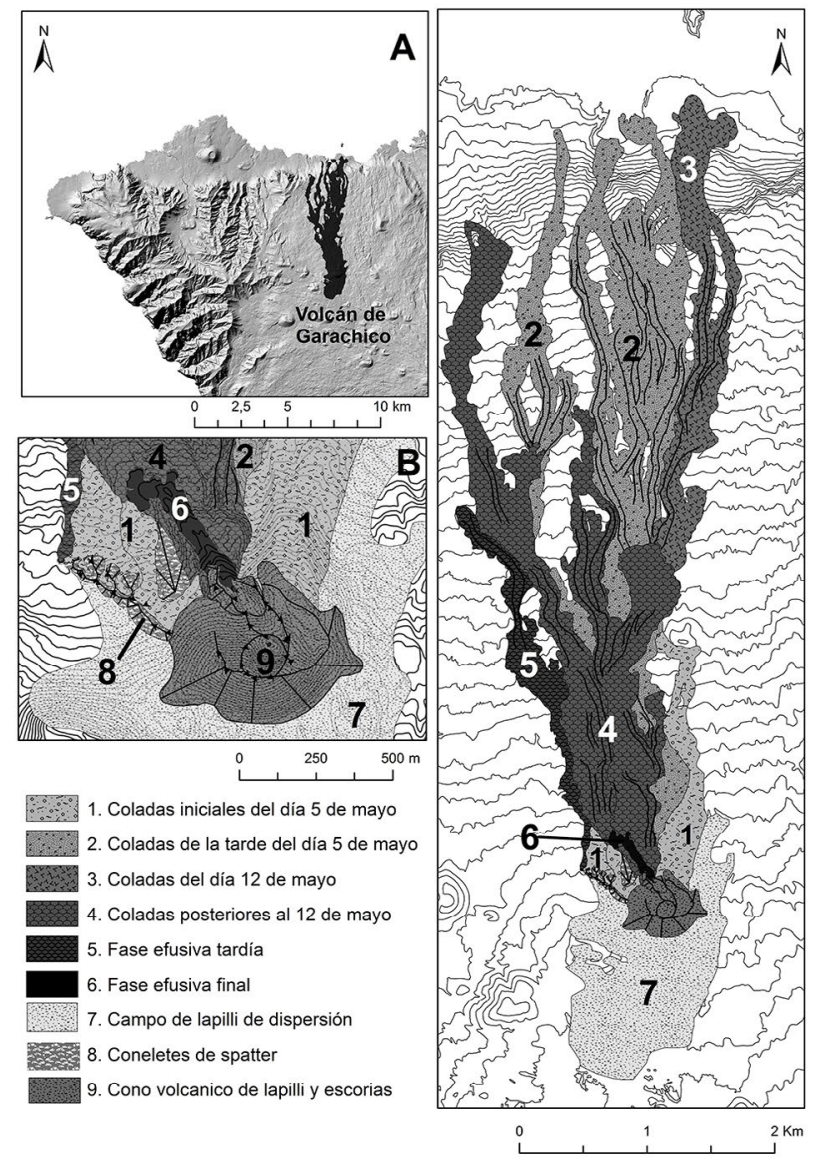

A: Localización. B.- Croquis morfológico de los centros de emisión. A la derecha, las unidades lávicas correspondientes a las distintas fases de emisión de la erupción de 1706.

Hacia las $7.00 \mathrm{~h}$ de la tarde, algunas coladas de tipo aa, tras recorrer las laderas unos $6,5 \mathrm{~km} \mathrm{y}$ con una velocidad de unos $925 \mathrm{~m} /$ hora, caían de modo precipitado por el tramo del paleoacantilado de 
400 metros de altura ubicado hacia el SW de la ciudad: "á las 7 de la tarde... se hechó sobre el camino que iba de Garachico á San Pedro de Daute, le entulló en parte, y consumió algunas viñas de San Pedro" (Martínez Fuentes, en Romero, 1991) (Fig. 5, no 2 y Fig. 6, a). La configuración arqueada del paleoacantilado motivó que las coladas de lava que saltaban el escarpe confluyesen a su pie, favoreciendo además la formación de grandes bolas de acreción. Las bolas de acreción constituyen fragmentos de carácter esférico, núcleo escoriáceo y superficie masiva, con tamaños que oscilan entre pocos centímetros a varios metros de diámetro. Estas bolas se forman como consecuencia del propio movimiento de la colada. Cuando la colada salta importantes desniveles, la velocidad que adquieren las bolas de acreción es mucho mayor que la de la propia colada de la que proceden, de modo que suelen emplazarse a decenas, o incluso a centenas de metros, más allá de los frentes activos de las mismas De este modo, aunque el frente de lava de estos brazos no avanzó mucho más allá, las bolas de acreción terminaron por caer al mar en el sector del puerto.

Dos horas más tarde, a las nueve de la noche, tres nuevos frentes digitados de dicha colada, alcanzaron el escarpe algo más hacia el este: "y á hora de las nueve de la noche se descolgaron por los riscos de La Atalaya y Barranco Hondo" (Fr. Juan Garcia, 1707, fol 1). Nuevamente, el trazado arqueado del escarpe motivó la confluencia de estos flujos al pie de los taludes, y su canalización por el antiguo barranco de Los Reyes favoreciendo su llegada al mar y la colmatación de la bahía (Fig. 5, n 2 y fig. 6, b1-b2 y b3). Estas coladas siguieron corriendo durante algunos días, retirando el mar unos 250 m (Martínez Fuentes, en Romero, 1991).

Figura. 6. Trazado de las coladas de la erupción de 1706

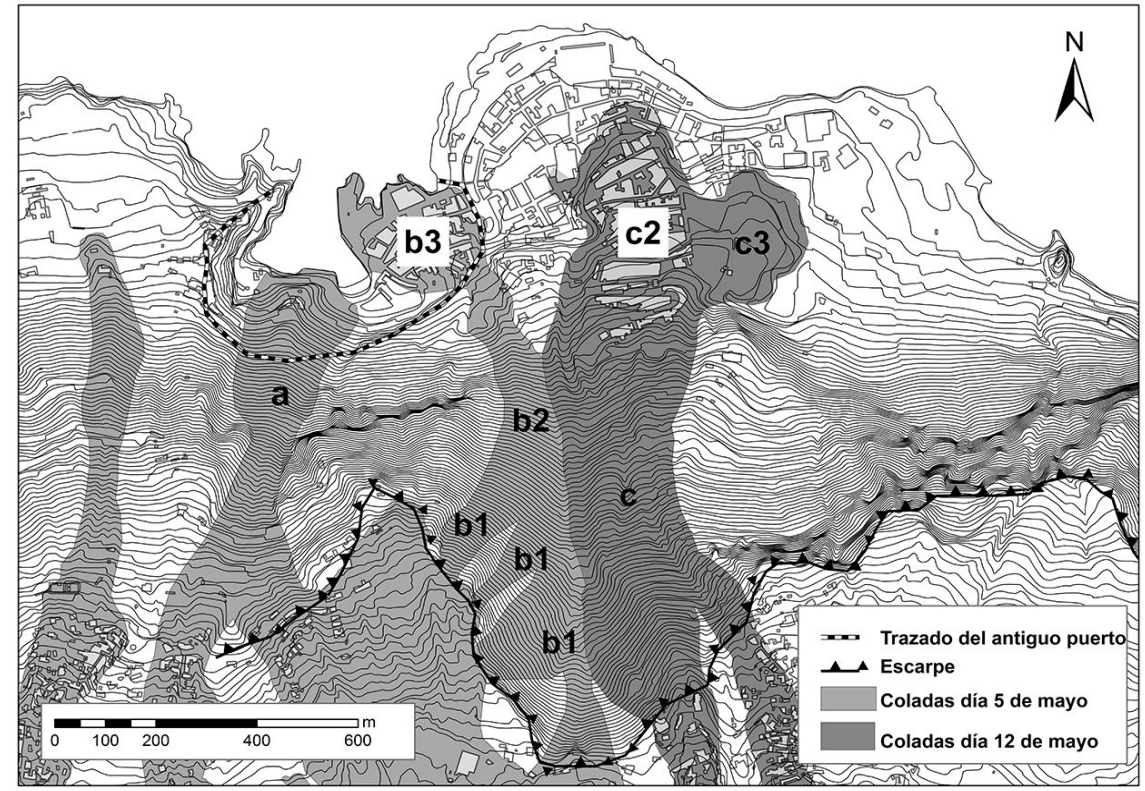

En gris claro las derramadas durante el 5 de mayo; en gris oscuro, las coladas del 12 de mayo de 1706. La línea punteada marca el límite del antiguo puerto.

El $12^{3}$ de mayo de 1706 , se confirmó un nuevo incremento de la actividad efusiva del cráter principal (Fig. $5, \mathrm{n}^{\circ}$ 3) y nuevas coladas alcanzaron el escarpe algo más al este que las anteriores. La obturación del barranco durante la fase efusiva anterior motivó un cambio en la dirección de los flujos en esta fase, que se derramaron hacia el norte. Durante el emplazamiento de estas coladas se formaron bolas de acreción de varios metros de diámetro que avanzaron más allá de sus frentes activos (Fig.6, c, cl y c2).

La mayor parte de las crónicas se detienen en este punto. Con posterioridad, solo sabemos que el día 28 de mayo, la colada tenía su frente a menos de $100 \mathrm{~m}$ de la costa A partir de esa fecha, debió producirse una reducción de la tasa de efusión, pues las coladas de fases posteriores se superponen a las anteriores y no llegaron en ningún caso a alcanzar la base del escarpe pre-litoral (Fig. 5, nº 5 y 6). La erupción terminó el 13 de Junio de 1706. El volcán había estado activo durante un período de unos 40 días.

3 La llegada a la ciudad de nuevas coladas se produjo el día 12 y no el 13 de mayo como habitualmente consta en la mayoría de los textos científicos, pues en el manuscrito de Fr. Juan García se afirma: "Fue este día víspera de la Ascensión del Señor 12 del dicho mes de Mayo á la noche en que se quemó" el Convento de San Francisco. 


\section{EL IMPACTO DE LA ERUPCIÓN DE 1706}

\subsection{Los peligros asociados al emplazamiento de las lavas de 1706}

Habitualmente, los peligros asociados a una erupción volcánica se establecen en función de la modalidad de los mecanismos eruptivos (hawaiano, estromboliano, etc), su VEI (Volcanic Explosivity Index), el tipo del material emitido y el área cubierta por los mismos. Como corresponde a una erupción de tipo estromboliano, con VEI 2, y de rasgos eminentemente efusivos, los peligros volcánicos de la erupción de 1706 están asociados fundamentalmente al emplazamiento de coladas de lava. El 82\% de la superficie cubierta por la erupción corresponde a flujos lávicos. De hecho, prácticamente no existe información acerca de la caída de cenizas volcánicas en la ciudad, salvo la brevísima alusión en un texto de 1803 [“... de monceaux des cendres occupent la place de Garachico"; "...montones de cenizas ocupan el lugar de Garachico"] (Bory de Sainte Vincent, 1803:291).

Una parte importante de los peligros vinculados a esta erupción es resultado de la constante ramificación del cuerpo principal de la colada en varios brazos a media que descendían en altitud acercándose a la costa.

Figura 7. Grabado en el que se representan las coladas cayendo por el escarpe prelitoral existente al sur de Garachico. A la imagen se le han añadido flechas de flujo lávico para identificar mejor las corrientes de lava

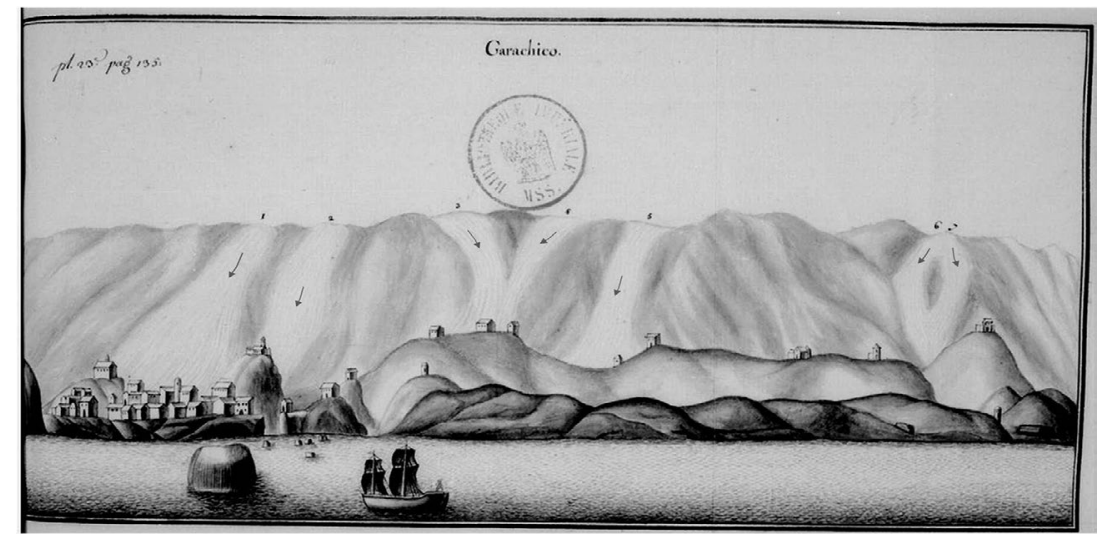

Fuente: Louis Feuillèe (1724)

De este modo, antes de saltar el cantil prelitoral las coladas aparecían ya individualizadas en seis brazos diferentes (ver Fig. 7). Este hecho contribuyó a una mayor extensión de los sectores directamente ocupados por las coladas y a la ampliación del espacio afectado durante el período activo. La ramificación de las coladas en varios brazos tuvo como consecuencia directa que los terrenos rodeados totalmente por ellas quedaran transitoriamente aislados e incomunicados del resto, lo que supone una ampliación del terreno afectado por la erupción de más de $1 \mathrm{~km}^{2}$.

Los daños producidos durante la erupción de 1706 en la Villa y Puerto de Garachico estuvieron causados por tres tipos de procesos vinculados al emplazamiento de las coladas de lava. Evidentemente, el más importante de todos ellos es resultado del arrasamiento y la destrucción provocada por la ocupación directa del terreno por la lava a medida que los distintos brazos lávicos fueron avanzando hacia la costa.

La existencia del acentuado cambio de pendiente impuesto por el escarpe prelitoral provocó la fragmentación brusca de las lavas y su colapso, dando lugar a la formación de bloques y fragmentos calientes que rodaron vertiente abajo y motivaron la generación de pequeños flujos piroclásticos (Francis, 1993; Scott, 1989). Algunos autores (Uriarte, 2006) tomando como base el texto de Bory de Saint Vincent de 1888 sobre esta erupción, señalan que durante la misma pudieron producirse muertes como consecuencia de una avalancha de rocas. Procesos de esta índole fueron observados durante la última erupción subaérea de Canarias, registrada en la isla de La Palma en 1971(Araña, 1999).

El impacto que las bolas de acreción tuvieron en la ciudad queda recogido en las crónicas que narran la erupción, en donde se señala como estas bolas, al chocar contra los edificios se fragmentaban, mostrando un núcleo incandescente que dio lugar a la generación de incendios, propagados con intensidad gracias a la construcción de los edificios con madera de tea: “...llegó hasta el convento de San Diego, Monjas de Santa Clara de este Lugar de Garachico, y aunque no entró, desde afuera mandó sus llamas en encendidos pedernales, que todo le abrasaron..."(En Darias Padrón, 1931: 39-40). 
Las elevadas temperaturas de las coladas produjeron procesos de irradiación térmica que dieron lugar a incendios, tanto en la vegetación como en las viviendas: “...Esse torrente se paró antes de tocar el convento de San Francisco, con sus llamas volantes, lo reduxo a cenizas..." (Martínez de Fuentes s XVIII, en Romero, 1991:506). A pesar de la confluencia de los distintos brazos lávicos al pie del acantilado, las coladas al penetrar en la plataforma redujeron drásticamente su velocidad. La fluidez y densidad de las lavas basálticas determinan que éstas no posean un alto poder destructor sobre estructuras edificadas (Ortiz y Araña, 1996), siempre que las edificaciones posean más altura que la propia colada. Sin embargo, las coladas que se derramaron en el interior de la plataforma, parcialmente desgasificadas y enfriadas al saltar el escarpe, pero aún calientes, tuvieron que aumentar su altura crítica para poder seguir fluyendo y vencer el mayor grado de viscosidad del fundido. Este proceso redujo su velocidad pero aumentó su potencia, llegando alcanzar hasta $20 \mathrm{~m}$ de altura en sus frentes, lo que evidentemente aumentó el poder destructivo de las mismas.

\subsection{El impacto de la erupción en Garachico y su entorno}

Los distintos peligros volcánicos descritos se organizan a partir de las dos unidades de paisaje reseñadas en sectores diferenciados de riesgo volcánico: escarpe y taludes de un lado, y plataforma costera de otro. En ambos casos, los riesgos están estrechamente vinculados a los elementos territoriales que caracterizan a cada uno de los espacios y que son definitorios de las costas de los rifts volcánicos de bajas tasas eruptivas.

En este sentido, los daños producidos por las coladas en las laderas superiores se relacionan fundamentalmente con la destrucción de áreas de cultivo, pero, en cuanto se produce la llegada de éstas al acantilado, se diversifica el efecto destructor de las mismas. No sólo por el espectacular salto de las corrientes de lava al precipitarse por el escarpe que multiplica su fuerza destructora, sino también por el contacto de éstas con una original geografía del paisaje asociadas a la pared costera. En efecto, la invasión de las coladas en sectores de bosques, aparte de las áreas cultivadas, dio lugar a incendios forestales que, aunque localizados de forma dispersa, multiplicaron y reforzaron los daños por el fuego (Cassares, 1709, fol2v). Otra de las consecuencias devastadoras del avance de las coladas por el acantilado fue la desaparición de un importante número de fuentes y manantiales, recursos naturales de primer orden para el uso agrario y abastecimiento urbano y portuario de la zona. Los impactos de las coladas sobre la plataforma costera, una vez alcanzada esta otra unidad de paisaje son de diferente naturaleza y destacan fundamentalmente por sus efectos catastróficos en otros elementos territoriales que la distinguen: la ciudad y la población de la villa de Garachico y su puerto.

\subsubsection{El impacto sobre la ciudad y el puerto de Garachico}

Es evidente que desde 1706, los frentes y taludes laterales de las coladas se han visto sometidos a una importante transformación asociada al crecimiento posterior de la ciudad. Por ello, para determinar el trazado y el límite de cada uno de los frentes de lava, es necesario acudir a la información proporcionada por los planos y croquis realizados con posterioridad a 1706 y en los que se representan de modo claro los principales brazos lávicos, (Riviere, 1741; M.R.P.M. Fray Andrés Castillo, 1775/1780; Francisco Coello, 1849; José Agustín Álvarez Rixo, 1883 o el croquis realizado por Nuñez de La Peña, s XVIII) En ninguna de estas fuentes gráficas se alude a la cronología de cada uno de esos frentes lávicos, que ha sido establecida siguiendo la información proporcionada por los textos históricos.

El análisis de la información obtenida de los documentos gráficos permite conocer con cierta precisión los daños ocasionados por los flujos lávicos. Estos datos han sido contrastados con datos históricos, topográficos y geomorfológicos, con el fin de determinar el trazado real presentado por las coladas en la ciudad y en el puerto sobre un mapa actual. Los elementos utilizados en este estudio han sido resumidos en la Fig. 8.

Los mayores daños estuvieron ocasionados por la sucesión de dos fases efusivas definidas, producidas durante el primer día de la erupción, 5 de mayo, y durante el día 12 de ese mismo mes. Las primeras coladas del día 5 de mayo, que penetraron en la bahía por el suroeste a las 7 de la tarde (Fig. 6, a), apenas dieron lugar a daños irreparables, pues no destruyeron edificaciones importantes; sólo las bolas de acreción penetraron en el mar pero sin modificar gravemente el antiguo puerto. No obstante, afectaron a algunos campos de cultivo dedicados a la viña de malvasía y fueron las causantes de la destrucción de las infraestructuras viarias que comunicaban la ciudad con el resto de las poblaciones del oeste de Tenerife, dejando a toda esta comarca incomunicada con el resto de la isla por el norte. 
Los brazos lávicos que se descolgaron a las 9 de la noche en el sector de Barranco Hondo (Fig. 6, b1) confluyeron hacia la base del escarpe (Fig. 6, b2). Esta colada (Fig. 6, b3), siguió el curso del Barrano de Los Reyes que terminaba en la playa, provocando la colmatación irreversible de la ensenada que servía de puerto. La existencia de este barranco preservó el área donde se ubicaba La Ermita de Los Reyes y la Finca Arango

Las corrientes de lava de la fase efusiva del día 12 de mayo afectaron de modo exclusivo al sector sur y oeste de la población y al corazón del núcleo urbano. Estas coladas tardías, una vez rebasado el escarpe, se digitaron al pie del talud en dos frentes distintos. Uno corrió hacia el norte hasta casi alcanzar la línea costera (Fig. 6, c1), afectando al núcleo de la población y el otro (Fig. 6, c2), se dirigió hacia el este destruyendo las estructuras agrícolas de la ciudad.

En esta fase se produjo la desaparición de los mejores campos de cultivo de los que se nutría la población, de los molinos y los sistemas de canalización de agua que permitían el riego y abastecían a la ciudad y de los humildes barrios de Los Morales y de San Telmo, incluida su ermita, que había sido trasladada en 1638 de su ubicación junto al mar por los destrozos que éste ocasionaba. Sólo un barrio ubicado en el sector meridional de la ciudad (Barrio de Los Reyes) no sufrió daños tan importantes, al estar situado a una cota altitudinal mayor. Durante esta fase, grandes bolas de acreción, al chocar contra los muros de las casas, contribuyeron a incrementar las pérdidas directas causadas por la lava, provocando incendios que se propagaron rápidamente.

Figura 8. Elementos urbanos y morfológicos que permiten reconstruir el trazado de las coladas sobre la ciudad de Garachico

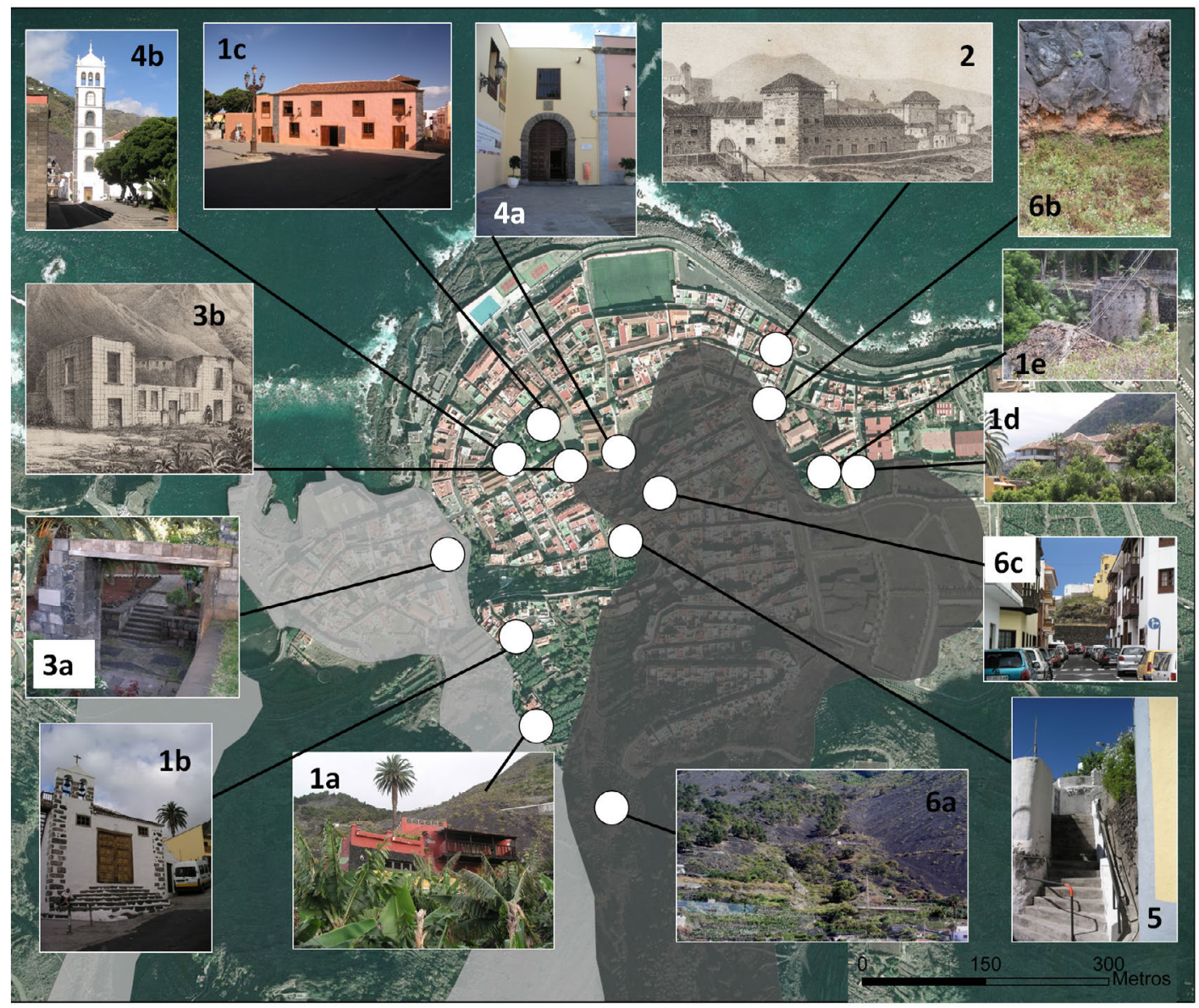

1. Edificios anteriores al s. XVIII sin daños por la erupción: la: Finca Arango (fines s. XVI). lb: Ermita de Los Reyes (s. XVI).1c. Casa de Los Marqueses de la Quinta Roja(s XVI). le: Molino de la Finca El Lamero (s. XVII) ld. Finca El Lamero (s XVII).

2. Construcciones previas afectadas parcialmente por la erupción pero conservadas con posterioridad y luego desaparecidas: Convento de Santa Clara, dañado parcialmente por bolas de acreción.

3. Elementos urbanos afectados por las coladas y conservados en la actualidad: 3a. Puerta de acceso al antiguo puerto. 3b. Palacio Condes de La Gomera (1666).

4. Edificios afectados y reconstruidos s. XVIII: 4a. Convento de San Francisco. 4b. Iglesia de Santa Ana.

5. Elementos actuales de la trama urbana vinculados a los frentes y taludes de las coladas.

6. Elementos morfológicos: 6a: Superposición de las coladas de las fases del 5, de color gris claro, y 12 de mayo de 1706, de color gris oscuro. 6b. Talud lateral modificado de la colada del 12 de mayo de 1706. 6c. Talud lateral escarpado de la colada del 12 de mayo de 1706. 
Esta fase afectó a todas las infraestructuras situadas en la Calle de Arriba, fundamentalmente religiosas y nobiliarias localizadas en torno al Convento de San Francisco. Desde este último edificio se propagó un incendio, favorecido por la utilización en las construcciones nobles de madera de tea, altamente inflamable, que asoló las casas existentes entre ese punto y la antigua playa del puerto, y que terminó por afectar gravemente a la Iglesia Parroquial de Garachico. Por primera vez en la historia de la ciudad, un desastre natural afectaba no sólo a la población de los barrios marginales sino que castigaba con rudeza al sector donde estaban instaladas las principales haciendas y los edificios más notables: conventos, iglesias, casas nobiliarias.

\subsubsection{El impacto sobre la población}

La erupción tuvo enormes repercusiones sobre la población, tanto de forma inmediata como a largo plazo. No se tiene constancia documental de los efectos de los primeros terremotos asociados a la erupción de 1706, pero la experiencia previa que supuso el evento volcánico de 1704-1705, con los innumerables daños generados por los sismos y la muerte de 16 personas, no hizo sino agravar la situación. Sólo durante la noche del 4 al 5 de mayo, cuando estos incrementaron su intensidad, el pánico se apoderó de los habitantes de Garachico obligándoles a refugiarse en las iglesias: "Prosiguióse la noche temerosa, y cada vez la gente más medrosa... pareciendole â alguno de afligido algún Polo del mundo está rendido, caminaban àcia los conventos... De este modo, Señor, se originaron los terremotos grandes ... con tal fiereza, qe. à todos conmobieron à tristeza......". (Cassares, 1709, fol. 4,5 y 6).

Ante el aumento de los ruidos y de las detonaciones en la cumbre se enviaron desde Garachico personas a reconocer el origen de todos estos fenómenos, quienes trajeron la noticia de que había reventado un nuevo volcán, que "embrabecido", bajaba hacia la ciudad (Cassares, 1709).

Cuando al atardecer del día 5 de mayo, se descolgaron por el escarpe las primeras coladas se produce el comienzo de la evacuación de los primeros habitantes de la ciudad, incluyendo los enfermos postrados. Varios autores narran la confusión generada en esos momentos: "Descubrieronle luego qe. atrevido [el volcán] por sobre un risco dava yà un bramido, onde halló unos ramos por trincheras y levantó unas llamas por vanderas, qe. haciendo yà alarde de lo ardiente fueron toque de marcha à nuestra gente... aquí fue del dolor el sentimiento, yà muchos se miraban sin aliento... abrieron, ò rompieron las clausuras, quando aquí fue mayor la confusion, al ver salir las hijas de Síon tropezando una en otra sin hablarse, y sin poder del susto recobrarse... Salieron igualmente á aquellas horas de sus casas muchissimas Señoras, sin adorno, rebueltas, asustadas, y al verse ir de su Patria desterradas... sacavan las enfermas que rasgaban el corazon al verlas, y clamaban, en los brazos de algunos qe. por lecho les previno lo horrible de aquel hecho.." (Cassares, 1709, fol 7v y 8).

Esta evacuación prosiguió a medida que las coladas fueron ocupando la ciudad. El pánico de la población debió alcanzar su punto álgido el día 12 de mayo, cuando junto a los procesos volcánicos se produjo un eclipse total de sol; ese mismo día las coladas alcanzaron el Convento de San Francisco, y los religiosos abandonaron la ciudad: "Los Religiosos del Convento de San Francisco se retiraron al lugar de Icod, habiendo consumido el Santísimo Sacramento el día que se quemó el Convento... Fué este día vispera de la Ascensión del Señor 12 del dicho mes de Mayo á la noche en que se quemó...". (Juan García Vicario, 1707, fol 3).

Esta vez las coladas se derramaron por el sector oriental de la ciudad; el día 28 de mayo uno de estos flujos lávicos se acercó peligrosamente a la costa, hasta situar sus frente a menos de 100 metros de la misma. Ello motivó la evacuación completa de la ciudad, pues se corría el riesgo de que una buena parte de la misma quedara aislada entre las coladas del 5 y 12 de mayo. Entonces: "Quedó el lugar desierto... El paraíso quedó en remedo del infierno..." (En Caballero Mújica, 2001: 319)

Aunque algunos autores señalan la muerte de algunas personas (Bory,1803), los cronistas contemporáneos afirman: "No sucedió fatalidad en que peligrase humana criatura" (Juan García Vicario,1707, fol 3).

Terminada la erupción, los habitantes regresaron a la ciudad, pero la pérdida del puerto fue irreparable. Perdido para el tráfico comercial, que era una de las funciones que explicaba la significativa proporción de población en Garachico, ésta emigró hacia otros puntos de la isla. La erupción contribuyó, de un lado, a la emigración de la población a las áreas circunvecinas a la ciudad (Icod de Los Vinos, La Orotava, Pto de la Cruz) y a la ocupación de territorios con escasos vecinos (Isora); de otro a un proceso de emigración de familias enteras a América, lo que ha sido calificado como una auténtica despoblación (Álvarez Rixo, 1701-1872 y Rodríguez Mendoza, 2003-2004). A corto plazo el impacto sobre la población fue demoledor.

Pero también la erupción supuso a largo plazo una pérdida notable de habitantes, tal y como se muestra en el gráfico de la evolución de la población de la ciudad entre 1582 y 1950 (Fig. 9). Garachico perdió 
en 1706 tres cuartas partes de su población y no volvió a alcanzar valores similares a los que había tenido durante los s XVI y XVII hasta bien avanzado el s XX.

Figura 9. Evolución de la población de Garachico entre 1522 y 1950. El descenso de la población a principios del s. XVIII está asociado de modo claro a la pérdida de la actividad comercial del puerto destruido durante la erupción de 1706.

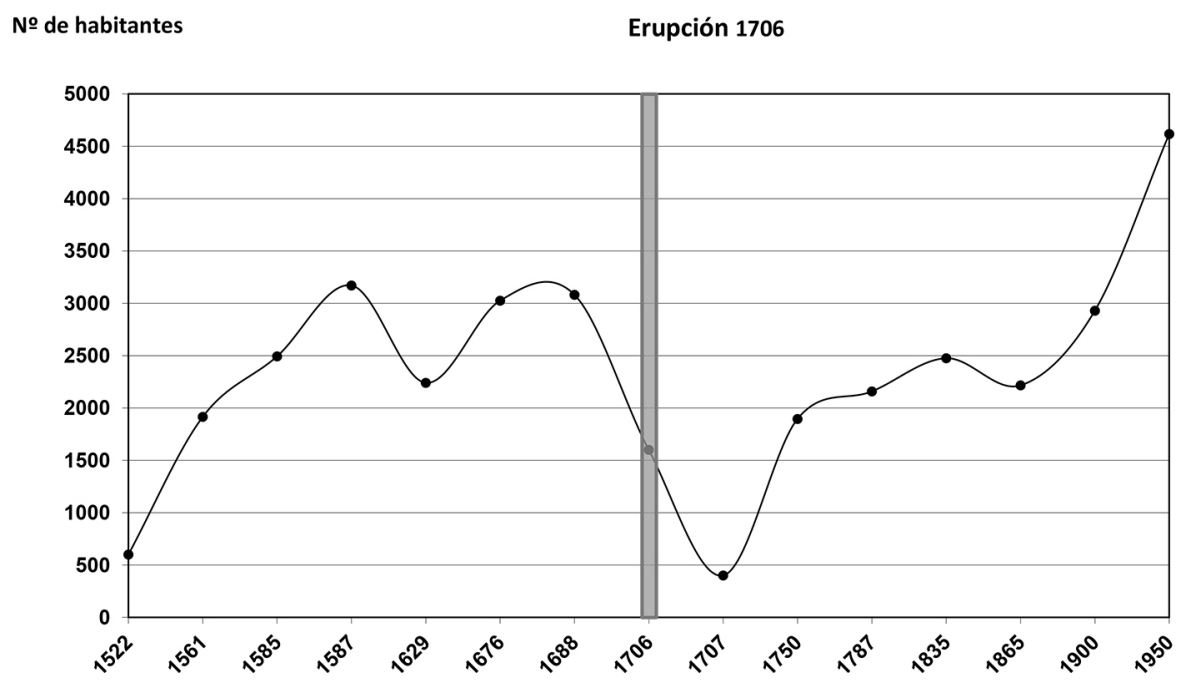

Fuentes: Acosta (1994), Hernández González (2002), Nuñez de la Peña (1676), Rosa Olivera (1978)

\section{CONCLUSIONES}

Volcanológicamente, la erupción de 1706 corresponde a un evento volcánico de carácter efusivo y de bajos índices explosivos (VEI 2), y por tanto muy moderado, cuyos peligros estuvieron vinculados esencialmente al emplazamiento de flujos lávicos. Sin embargo, esta erupción constituye un excelente ejemplo de cómo un evento de baja peligrosidad puede convertirse en un desastre. Witham (2005) señala que el número de personas evacuadas durante el fenómeno volcánico debe tomarse en consideración para calificar una erupción como desastre, y según la CRED, el requisito en este sentido para recibir tal calificación es que la erupción sea la causa de la muerte de, al menos, diez personas o haya afectado a un número superior a cien. Con los datos existentes a cerca de la población de Garachico (1600 habitantes en 1706 y tan sólo 400 en 1707, un año después), se puede afirmar que este suceso volcánico afectó a un $75 \%$ de la población, lo que la convierte, sin lugar a dudas, en un auténtico desastre.

El elevado nivel de riesgo alcanzado estuvo asociado al avance de las coladas por las laderas de un rift volcánico de bajas tasas eruptivas con una original configuración espacial. En esta configuración fue clave no solo la orografía sino también otros elementos territoriales que se combinaron para reforzar y diversificar los peligros y el impacto final causado por las lavas. La topografía condicionó el recorrido de las coladas y el peculiar modo de emplazamiento de las mismas. La existencia de rupturas bruscas de pendiente en el sector prelitoral y el trazado de la línea superior del escarpe favorecieron la confluencia de los flujos al pie del paleoacantilado, y dieron lugar a la formación de pequeños flujos piroclásticos, bolas de acreción y a cambios de la viscosidad del fundido que incrementaron el poder destructivo de las lavas.

Asimismo, la presencia de bosques debido a condiciones climáticas favorables, la abundancia de agua en el escarpe a través de fuentes y manantiales, los suelos naturales en los taludes y de "préstamo" sobre la plataforma, junto a un excepcional puerto comercial, se concentraban en un territorio de reducidas dimensiones, rico en recursos naturales, pero también muy densamente poblado por la presencia de una próspera ciudad. Todos estos elementos se combinaron en el espacio creando una particular geografía que sustentaba un escenario muy vulnerable frente a los procesos eruptivos. Es este escenario el que explica que la erupción de 1706 pueda ser considerada como una de las catástrofes volcánicas más importantes del archipiélago canario.

En definitiva, el estudio del impacto de las coladas de 1706 en la ciudad de Garachico pone en evidencia que los peligros vinculados al emplazamiento de los flujos lávicos, están condicionados también por la geografía del paisaje afectado por la erupción. El escenario geográfico controla decisivamente la 
intensidad, la diversidad y la organización territorial de los impactos, por lo que su estudio constituye un valioso modelo para el establecimiento de los riesgos asociados a futuras erupciones en sectores de rifts volcánicos.

Desde este punto de vista conviene señalar además que la vulnerabilidad frente a este tipo de procesos eruptivos ha ido cambiando con el tiempo. Dieciocho años antes de la erupción, en 1688, Tenerife presentaba una población de 51.867 habitantes Desde el fenómeno volcánico de 1706, la isla ha multiplicado su población por 17, y gran parte de ésta se concentra en los sectores de medianías bajas y costeros de los rifts volcánicos. No cabe duda, por tanto, que este hecho hace de dichas áreas uno de los escenarios geográficos de mayor riesgo volcánico de las islas.

\section{RECURSOS ELECTRÓNICOS}

ACOSTA GARCÍA, C. (1994): Apuntes generales sobre la historia de Garachico. Santa Cruz de Tenerife. ÁlVAREZ RIXO, J.A. (1994): Anales del Puerto de la Cruz y de La Orotava. 1701-1872. Cabildo Insular de Tenerife. Patronato de Cultura del Ayuntamiento del Puerto de La Cruz. Tenerife

ANCOCHEA, E., FUSTER, J.M., IBARrOlA, E., CENDrERO, A., COEllO, J., HERNÁN, F., CANTAGREL, J.M. y JAMOND, C.(1990): "Volcanic evolution of the island of Tenerife (Canary Islands) in the light of the new K/Ar data". Journal of Volcanology and Geothermal Research n ${ }^{\circ} 44$, pp. 231-249.

ARAÑA, V. (1999): "Comentarios sobre la erupción del volcán Teneguía en 1971" Enseñanza de las Ciencias de la Tierra, (7.3).

ARAÑA, V., FELPETO, A., ASTIZ, M., GARCÍA, A., y ORTIZ, R. (2000): "Zonation ot the main volcanic hazards (lava flows and ash fall) in Tenerife. A proposal for surveillance networtk". Journal of Volcanology and Geothermal Research, $\mathrm{n}^{\circ} 103$, pp. 377-391.

del ARCO et al. (2006): Mapa de vegetación de Canarias. Ed. GRAFCAN. Sta. Cruz de Tenerife.

BELLIDO MULAS, F. y GÓMEZ SAINZ DE AJA, J.A. (1989): Icod de Los Vinos. 1103-III. Mapa Geológico España, 1:250.000. IGME. http://info.igme.es/cartografia/datos/magna50/jpg/d11 jpg/Editado MAGNA50 1103IIIA.jpg

BELTRÁN, E. (2000): El paisaje natural de los volcanes históricos de Tenerife. Ed. Fundación Mapre-Guanarteme. Las Palmas de Gran Canaria.

BORY DE SAINT VINCENT, J.B. (1803): Essais sur les îles Fortunées et l'antique Atlantide ou Précis de l' histoire generales de l' Archipel des Canaries. París. Bandomin.

CABALlERO MUJICA, F. (2001): Documentos episcopales canarios. Tomo III de Bernardo Vicuña Suazo a Fco. Javier Delgado y Venesas (1691-1768). Real Sociedad Económica de Amigos del País. Las Palmas de Gran Canaria.

CARracedo J.C., PATERne, M., GUIllou, H., PÉREZ TORRADO, F.J., PAis, R., RODRÍGUEZ BADIOLA, E. y HANSEN, A. (2003): "Dataciones radiométricas (14C y K/AR) del Teide y el Rift Noroeste, Tenerife, Islas Canarias". Estudios Geológicos, n59 pp. 15-29.

CARRACEDO, J.C., GUILlOU, H., RODRÍGUEZ BADIOLA, E., PÉREZ TORRADO, FJ., RODRÍGUEZ GONZÁlEZ, A., PARIS, R., TROLL, V., WIESMAIER, S., DELCAMP, A. y FERNÁNDEZ-TURIEL, J.L. (2009): "La dorsal NE de Tenerife: Hacia un modelo del origen y evolución de los rifts de islas oceánicas". Estudios Geológicos, nº5, pp. 5-47.

CASSARES, D.J. (1709): Breve narrativa de la lamentable y lastimosa desgracia de Garachico; hecha, y consagrada a Ntro. Iltmo. y Reve.mo Sor Dn Juan Ruiz Simón, Dignissimo Obispo de estas Yslas de Canaria. Ms 83.II.10 (F.73-87r) de la Biblioteca de la Universidad de La Laguna.

CIORANESCU, A. (1977): Garachico. Aula de Cultura del Excelentísimo Cabildo Insular de Tenerife. Selecciones Gráficas.

DARIAS PADRÓN, D. (1931): "La Villa y puerto de Garachico. Cuadros históricos". Revista de Historia. Facultad de Filosofía y Letras de la Universidad de La Laguna Tomo IV. Año VII, n 29 y 30.

DÁVILA CÁRDENAS, P. M. (1737): Constituciones y nuevas addiciones Sinodales del obispado de las Canarias, Madrid.

DE LA ROSA OLIVERA, L. (2005). El bando de Daute. Ediciones Idea.

ESCRIBANO, G. (2003): "Primera campaña de prospección subacuática del puerto de Garachico", Investigaciones Arqueológicas en Canarias . Las Palmas de Gran Canaria. n 7, pp. 443-460.

FEUILLÈE, L. (1724): Manuscript of Central Library of National Museum. France. http://gallica.bnf.fr/ ark:/12148/btv1b90616737/f1.item 
FRANCIS, P. (1993): Volcanoes. A planetary perspective. Oxford. University Pres

FRUTUOSO, G. (1522-1591): Saudades da terra. Livro primeiro, National Library of Canada Cataloguing in Publication Data.pag 94. http://www.sealegacy.com/LivroPrimeiro.pdf

GARCÍA, J. (1707): Papeles referentes al Convento franciscano de Nuestra Señora de los Ángeles, de Garachico, Tenerife [Manuscrito] MSS_008957. Biblioteca Nacional.

HERNÁNDEZ GONZÁLEZ, M. (2002): Tenerife. Patrimonio histórico y Cultural. Ed. Rueda. Madrid.

MARTÍN RODRÍGUEZ, F.G. (1986): La primera imagen deCanarias. Los dibujos de Leonardo Torriani. Colegio Oficial de Arquitectos de Canarias. Santa Cruz de Tenerife.

MARTÍNEZ DE FUENTES, F. (s. XVIII): MS Vida literaria. Tomo II. fol 169-170. MS del Archivo de la Sociedad Económica de La Laguna.

MARTÍNEZ GALINDO, P.M. (1998): La vid y el vino en Tenerife en la primera mitad del siglo XVI. Instituto de Estudios Canarios. La Laguna.

NÚÑEZ DE LA PEÑA, J. (1994): Conquista y antigüedades de las islas de la Gran Canaria y su descripción. Con muchas advertencias de sus Privilegios, Conquistadores, Pobladores, y otras particularidades en la muy poderosa Isla de Tenerife, Madrid-Las Palmas.

ORTIZ, R Y ARAÑA,V. (1996): "Daños que pueden producir las erupciones". En Ortiz (Ed): Riesgo volcánico. Serie Casa de los Volcanes. Servicio de Publicaciones del Cabildo Insular de Lanzarote.

RODRÍGUEZ MENDOZA, F. (2003-2004): La emigración del noroeste de Tenerife a América durante 1750-183. Servicio de Publicaciones de la Universidad de La Laguna. Serie Tesis Doctorales. Soportes audiovisuales e informáticos. ftp://tesis.bbtk.ull.es/ccssyhum/cs163.pdf

RODRÍGUEZ YANES, J.M (1988): Aproximación al estudio del Antiguo Régimen en la comarca de Daute. Tenerife 1500-1750. Aspectos demográficos, económicos y sociales. Archipiélago Canario S.L. Tenerife.

RODRÍGUEZ YANES, J.M. (1988): El Agua en la Comarca de Daute durante el siglo XVI. Aula de Cultura del Excelentísimo Cabildo Insular de Tenerife. Santa Cruz de Tenerife.

ROMERO, C. (1991): Las manifestaciones volcánicas históricas del Archipiélago Canario. Ed. Consejería de Política territorial. Gobierno de Canarias.

ROMERO, C. y BELTRÁN, E. (2007): La erupción de Arenas Negras, Evolución de un paisaje volcánico Ed. Viceconsejería de Medioambiente del Gobierno de Canarias. Sta. Cruz de Tenerife.

SCOT, W.E. (1989): "Volcanic and related hazards". In: Tilling (Ed) Volcanic hazards. American Geophysical Unión, pp. 9-23.

TORRIANI, L. (1592-1599): Descripción de las Islas Canarias. Tradución, introducción y notas por A. Cioranescu. Goya Ediciones. Sta. Cruz de Tenerife. 1959.

TOUS MELIÁ, J. (1996): Tenerife a través de la cartografía (1588-1899). Ed. Museo militar Regional de Canarias y Ayuntamiento de San Cristóbal de La Laguna. Madrid.

TOUS MELIÁ, J. (1997): Descripción Geográfica de Las Islas Canarias de Don Antonio Riviere [1740-1743]. Museo Militar Regional de Canarias.

URIARTE, C. (2006): Literatura de viajes y Canarias. Tenerife en los relatos de viajeros franceses del s XVIII. Biblioteca de Historia. Ministerio de Educación y Ciencia, CSIC.

VIERA y CALVIJO, J. (1786): Noticias de la historia General de las Islas de Canarias. Tomo III, Volcán que en 1706 destruye el lugar y Puerto de Garachico. pp. 355-357. Madrid.

WITHAM, C. S. (2005): "Volcanic disasters and incidents: a new database". Journal of Volcanology and Geothermal Research, 148(3), pp. 191-233.

YANES, A y BELTRÁN E. (2009): “1250 Acantilados con vegetación endémica de las costas macaronésicas”. En Bases ecológicas preliminares para la conservación de los tipos de hábitat de interés comunitario en España. Red Natura 2000. Ministerio de Medio Ambiente y Medio Rural y Marino. Secretaría General Técnica. Centro de Publicaciones. 98 pp

YANES, A., LUIS, M. y ROMERO, C. (1988):"La entidad geográfica de las Islas Bajas Canarias". Ería, pp. 259-269 